\title{
PENGARUH RELAKSASI LIMA JARI TERHADAP TEKANAN DARAH PENDERITA CHRONIC KIDNEY DISEASE
}

\author{
Shindi Hapsari, Dewi Puspitasari \\ Prodi S1 Keperawatan, STIKes Karya Husada Semarang Jl. Kompol R. Soekanto No. 46 Semarang \\ *shindihapsari@yahoo.com
}

\begin{abstract}
ABSTRAK
Penyakit Cronic Kidney Diseases (CKD) merupakan kondisi kegangguan fungsi ginjal yang progresif dan irreversible. Penanganan pasien CKD dilakukan hemodialisa, menimbulkan masalah tekanan darah tinggi. Perlakuan relaksasi terbimbing lima jari efektif dalam mengatasi hipertensi. Tujuan penelitian ini untuk mengetahui pengaruh terapi relaksasi metode lima jari terhadap tekanan darah pada pasien CKD di Ruang Hemodialisa Rumah Sakit Ken Saras. Metode penelitian quasi experiment dengan one group pre and post test design without control group.Sampel 20 pasien dengan hemodialisa, dengan teknik random sampling dengan minimal size experiment. Perlakukan terapi relaksasi genggam lima jari diberikan selama 15 menit kemudian menggunakan Sphygmomanometer untuk mengukur tekanan darah responden. Analisis statistic yang digunakan yaitu uji dependen t-test pada taraf signifikansi 0.05 . Hasil menunjukkan nilai $p$-value 0,00 , ada pengaruh yang signifikan. Kesimpulan Ada pengaruh terapi relaksasi metode lima jari terhadap tekanan darah pada penderita CKD.
\end{abstract}

Kata Kunci: relaksasi metode lima jari; tekanan darah; CKD

\section{THE EFFECT OF FIVE FINGER RELAXATION ON BLOOD PRESSURE OF CHRONIC KIDNEY DISEASE PATIENTS}

\begin{abstract}
Chronic Kidney Diseases (CKD) is a progressive and irreversible condition of kidney function impairment. CKD patients are treated with hemodialysis, which causes high blood pressure problems. The five-finger guided relaxation treatment is effective in overcoming hypertension. The purpose of this study was to determine the effect of the five-finger method of relaxation therapy on blood pressure in CKD patients in the Hemodialysis Room of Ken Saras Hospital. The research method was quasi-experimental with one group pre and post-test design without a control group. A sample of 20 patients is on hemodialysis, using a random sampling technique with a minimum experiment size. The five-finger handheld relaxation therapy was given for 15 minutes and then used a sphygmomanometer to measure the respondent's blood pressure. The statistical analysis used is the t-test dependent test at a significance level of 0.05 . The results of the statistical test dependent $t$-test $p$-value 0.00 ( $p$-value $<0.05)$ there is a significant effect. There is an effect of five finger relaxation therapy on systolic and diastolic blood pressure in patients with CKD.
\end{abstract}

Keywords: five finger relaxation method; blood pressure; chronic kidney disease 


\section{LATAR BELAKANG}

Cronic Kidney Disease (CKD) atau Gagal Ginjal Kronik merupakan kondisi gangguan fungsi ginjal yang progresif dan irreversible. Tubuh gagal untuk mempertahankan metabolisme dan keseimbangan cairan dan elektrolit, sehingga menyebabkan uremia (retensi urea dan sampah nitrogen lain dalam darah (Brunner, 2010) CKD merupakan masalah kesehatan yang berkembang pesat. Sebanyak $11 \%$ penduduk Amerika Serikat atau 19,2 juta orang mengalami gagal ginjal kronik. Studi GBD 2015 juga memperkirakan bahwa, pada 2015, 1,2 juta orang meninggal karena gagal ginjal (Black \& Hawks, 2021). Penyakit gagal ginjal di Indonesia menempati urutan ke 10 dalam penyakit tidak menular (Depkes RI, 2018)

Gagal ginjal bermula penyakit tidak menular lain seperti tekanan darah tinggi. Ginjal normal memiliki 1 juta nefron (unit satuan ginjal) yang berpengaruh terhadap laju filtrasi glomerulus. Ginjal memiliki kemampuan untuk menjaga laju filtrasi glomerulus dengan meningkatkan kerja nefron yang masih sehat ketika ada nefron yang rusak. Sedangkan kompensasi yang dilakukan tubuh menyebabkan hiperfiltrasi dan kompensasi hipertrofi pada nefron yang sehat. Selanjutnya CKD akan menyebabkan edema (baik edema perifer maupun edema paru), hipertensi, penyakit tulang, hiperkalsemia, dan anemia(Brunner, 2010; Husaini, 2020; Taruna, 2014) Hipertensi dan hiperfiltrasi pada glomerulus merupakan faktor yang berpengaruh besar dalam progresivitas penyakit ginjal kronis (Brunner, 2010)

Pasien CKD yang menjalani hemodialisis akan mengalami berbagai masalah yang dapat menimbulkan perubahan atau biologi, psikologi, social, dan spiritual. Masalah yang seringkali ditemukan pada pasien CKD yaitu ketidakstabilan tekanan darah. Gangguan tekanan darah yang dialami pasien CKD yaitu hipertensi. Pasien CKD mengalami Hipertensi dengan tekanan darah pre hemodialisa 150/100 mmHg dan post hemodialisa 130/ 80 $\mathrm{mmHg}$, hal ini menunjukkan tekanan darah yang tinggi pada pasien CKD dengan hemodialisa (Arthaeski, 2019; Sulistyarini, 2013) Hipertensi menjadi salah satu faktor pemicu terjadinya penyakit gagal ginjal, karena hipertensi yang berlangsung lama dapat mengakibatkan perubahan-perubahan struktur pada arteri di seluruh tubuh.(HEMODIALISIS \& SARI, n.d.)

Terapi yang dapat digunakan untuk mengatasi hipertensi terdiri dari terapi farmakologi dan non farmakologi. Terapi non farmakologi untuk mengatasi hipertensi yaitu terapi pengaturan diri, terapi psikologi, dan terapi relaksasi. Terapi relaksasi dilakukan dengan relaksasi nafas dalam, relaksasi otot progresif, latihan pasrah diri, terapi musik dan aromaterapi (Aswad \& Susanto, 2019) Salah satu terapi yang bisa dilakukan untuk mengatasi ketidakseimbangan tekanan darah dan gangguan kualitas tidur yaitu relaksasi. Relaksasi merupakan suatu prosedur dan teknik yang bertujuan untuk mengurangi ketegangan dan kecemasan, dengan cara melatih pasien agar mampu dengan sengaja untuk membuat relaksasi otot-otot tubuh setiap saat, sesuai dengan keinginan. Menurut pandangan ilmiah, relaksasi merupakan suatu teknik untuk mengurangi stres dan ketegangan dengan cara meregangkan seluruh tubuh agar mencapai kondisi mental yang sehat (Aswad \& Susanto, 2019)

Terapi relaksasi bertujuan untuk menimbulkan rasa nyaman atau relaks. Keadaan relaks pada tubuh menstimulus otak memproduksi endorphrin yang berfungsi sebagai analgesik alami tubuh dan dapat meredakan rasa nyeri (keluhan-keluhan fisik). Selain itu, dalam keadaan relaks tubuh akan mengaktifkan sistem saraf parasimpatis yang berfungsi untuk menurunkan detak jantung, laju pernafasan dan tekanan darah. Salah satu terapi relaksasi yang bisa dilakukan yaitu relaksasi metode lima jari(Aswad \& Susanto, 2019; Sulistyarini, 2013)

Relaksasi genggam lima jari merupakan tehnil relaksasi dengan metode pembayangan atau imajinasi dengan lima jari sebagai alat bantunya. Di dalam konsep intervensi 
keperawatan, tehnik relaksasi untuk membantu mengurangi beban sakit yang dialami pasien ada beberapa seperti guided imagery, relaksasi nafas dalam. Dasar dalam melakukan relaksasi untuk pasien dengan media yang perawat dan pasien mampu melakukannya.

Salah satu tindakan mandiri perawat yang mampu mengatasi ketidakstabilan tekanan darah yaitu relaksasi. Adapun metode yang sudah pernah dilakukan oleh perawat di ruangan tersebut yaitu melakukan nafas dalam. Tindakan tersebut tidak terlalu signifikan untuk mengurangi gangguan. Penelitian ini dilakukan untuk mengetahui pengaruh tekanan darah pada pasien hemodialisa setelah dilakukan terapi relaksasi dengan metode genggam lima jari ini.

\section{METODE}

Penelitian ini adalah penelitian kuantitatif dengan desain quasy experiment pendekatan one group pre post test without control design untuk mengetahui pengaruh terapi relaksasi metode lima jari terhadap tekanan darah penderita CKD di Rumah Sakit Ken Saras. Populasi dalam penelitian ini adalah seluruh pasien CKD yang menjalani terapi Hemodialisa di RS Ken Saras Kabupaten Semarang
Menggunakan teknik random sampling yang diperoleh oleh 20 responden dengan minimal size experiment dengan kriteria inklusi: Responden pasien CDK yang yang menjalani Hemodialisa grade III yang menjalani hemodialisa, berusia dewasa awal-akhir ( 2050 tahun), kesadaran baik composmentis. Responden dilakukan pengukuran tekanan darah, sebanyak $3 x$ yang akan diambil ratarata sebagai data pre test, penggukuran tekanan darah dilakukan dalam posisi berbaring semifowler pada saat sebelum dilakukan hemodialisa. Pemberian terapi relaksasai lima jari dilakukan saat pasien menjalani hemodialisa selama 15 menit. Kemudian setelah semua terapi diberikan tekanan darah di ukur untuk mengetahui hasil setelah diberikan terapi. Hasil pengukuran tekanan darah pre dan post test. Hasil tersebut dilakukan uji normalitas menggunakan sapiro wilk karena jumlah responden $<50$. Hasil uji normalitas diperoleh $p$-value $>0,05$ yang berarti data berdistribusi normal. Selanjutnya dilakukan uji pengaruh menggunakan uji dependent T-test. Penelitian ini dinyatakan telah Iulus tinjauan etis oleh Komite Etika Penelitian STIKES Karya Husada Semarang dengan nomor 1487/KH.KEPK/X/2019

\section{HASIL}

Tabel 1. Tekanan Darah Sebelum Dan Sesudah Perlakuan Relaksasi Metode 5 Jari Pada Pasien Hemodialisa Di Rumah Sakit Ken Saras $n=(20)$

\begin{tabular}{cccccc}
\hline Variabel & Mean & SD & Min & Max \\
\hline Tekanan darah sistolik pre test & 176,1 & 13,69 & 143 & 211 \\
Tekanan darah sistolik post test & 153,8 & 8,57 & 139 & 173 \\
\hline $\begin{array}{c}\text { Tekanan darah diastolik pre test } \\
\begin{array}{c}\text { Tekanan darah diastolik post } \\
\text { test }\end{array}\end{array}$ & 98,8 & 8,58 & 87 & 112 \\
\hline
\end{tabular}

Diketahui bahwa pada kelompok perlakuan relaksasi metode lima jari diperoleh mean nilai tekanan darah sistolik pre test sebesar 176,1 mmHg dengan standar deviasi sebesar 13,69. Pada pengukuran post test diperoleh rata- rata tekanan darah sistolik 153,8 $\mathrm{mmHg}$ dengan standar deviasi sebesar 8,57. Nilai tekanan darah diastolik pre test sebesar $98,8 \mathrm{mmHg}$ dengan standar deviasi sebesar 8,58. Lalu dilakukan post test diperoleh rata- rata tekanan darah diastolik $90,2 \mathrm{mmHg}$ dengan standar deviasi sebesar 6,18 
Berdasarkan tabel tersebut dapat diketahui bahwa hasil perlakuan relaksasi terbimbing metode lima jari diperoleh mean pre test tekanan darah sistolik 176,1 $\mathrm{mmHg}$ turun menjadi 153,8 mmHg. Hasil uji menunjukkan nilai $p$ value 0,000 sehingga dapat disimpulkan relaksasi metode lima jari berpengaruh menurunkan tekanan darah sistolik pasien hemodialisa. Hasil perlakuan relaksasi terbimbing metode lima jari diperoleh mean pre test tekanan darah diastolik $98,8 \mathrm{mmHg}$ turun menjadi 90,2 mmHg. Hasil uji beda menunjukkan nilai $p$ value 0,000 sehingga dapat disimpulkan relaksasi metode lima jari berpengaruh menurunkan tekanan darah diastolik pasien hemodialisa di Rumah Sakit Ken Saras

\section{PEMBAHASAN}

Hasil penelitian bahwa hasil setelah pasien dilakukan relaksasi dengan metode lima jari, tekanan darah sistolik 176,1 $\mathrm{mmHg}$ turun menjadi $153,8 \mathrm{mmHg}$ dan tekanan siastolik semula $98,8 \mathrm{mmHg}$ turun menjadi $90,2 \mathrm{mmHg}$. Hal tersebut menunjukkan adanya perubahan pada tekanan darah pasien CKD yang sedang menjalani hemodialisa. Perlu diketahui bahwa tekanan darah adalah tekanan yang ditimbulkan pada dinding arteri. Tekanan ini dipengaruhi beberapa faktor seperti curah jantung, ketegangan arteri, volume, dan laju serta kekuatan (viskositas) darah. Tekanan darah terjadi karena fenomena siklis. Tekanan puncak terjadi saat jantung beristirahat. Tekanan darah biasanya digambarkan sebagai rasio tekanan sistolikik terhadap tekanan diastolikik, dengan nilai dewasa normalnya berkisar dari 100/60 mmHg sampai 140/90 $\mathrm{mmHg}$. Rata-rata tekanan darah normal biasanya 120/80 mmHg (Brunner, 2010; Taruna, 2014)

Peningkatan tekanan darah yang dialami oleh seorang dengan penyakit Chronic Kidney Disease dapat meningkat bahkan berdampak pada fisik dan psikologis sehingga dapat berpengaruh pada kualitas kehidupan. (Essy, 2019) Hipertensi yang dimiliki oleh penderita CKD, merupakan factor resiko. Hemodialisa yang dijalani untuk meringankan gejala yang ditimbulkan karena kegagalan ginjal menjadi terapi utama bahkan harus dijalani selama hidup pasien. (Handayani \& Rahmayati, 2017) Haemodialisa bertujuan membantu memulihkan kondisi penderita gagal ginjal. Gangguan hemodinamik saat hemodialisa seperti peningkatan tekanan datah. (Brunner, 2010) Peningkatan darah ini dapat merusak pembuluh darah pada ginjal dan memperberat kesurakan pada ginjal. (Brunner, 2010)

Penatalaksanaan masalah hipertensi pada pasien gagal ginjal dapat menggunakan dua terhnik yakni tehnik farmakologi dan non farmakologi. Tindakan farmakologi membantu untuk menurunkan tekanan darah dengan inhibitor system saraf simpatik, system rennin angiotensi aldosteron.(Lutfiani \& Kurnia, 2021) Sedangkan non farmakologi dapat diberikan dengan metode genggam jari.

Penurunan tekanan darah setelah mendapatkan relaksasi lima jari dapat dijelaskan bahwa di dalam sistem saraf manusia terdapat sistem saraf pusat dan sistem saraf otonom pada kondisi relaks, tubuh akan mengalami fase istirahat sehingga tubuh akan mengaktifkan sistem saraf parasimpatis. Bekerjanya saraf parasimpatis menyebabkan terjadinya penurunan detak jantung, laju pernafasan dan penurunan tekanan darah (Muhammadiyah, 2017)

Mekanisme yang terjadi penderita hipertensi pada CKD dengan hemodialisa yang lama akan membuat pasien jenuh merasa putus asa, beban sangat berat, takut akan kondisinya sehingga akan memunculkan kortisol yang akan membuat vasokonstriksi pembuluh darah, (Brunner, 2010; HEMODIALISIS \& SARI, n.d.; Lutfiani \& Kurnia, 2021) susah tidur, lapang pandang sempit mengakibatkan tekanan darah tinggi. salah satu faktor yang berperan penting mempengaruhi tekanan darah yaitu emosi dan depresi gangguan psikososial. Relaksasi dengan metode lima jari yang dilakukan akan membimbing pasien mengenai keadaan yang membahagiakan bersama orang tersayang, apresiai pada dirinya, secara psikologis akan membuat pasien merasa bahagia, membuat penderita hipertensi merasa nyaman, tenang, 
beban masalah terasa hilang sehingga akan mengaktifkan endorpin sehingga membuat vasodilatasi pembuluh darah sehingga tekanan darah akan menurun. (Arthaeski, 2019; Sulistyarini, 2013)

Secara psikologis, pelatihan relaksasi membuat penderita hipertensi merasa relaks yang selanjutnya perasaan relaks tersebut mengurangi rasa ketidaknyamanan dan membuat mereka menjadi tenang, perasaan cemas serta khawatir menjadi berkurang. Penderita hipertensi merasa lebih dapat mengendalikan emosinya jika menghadapi halhal yang tidak menyenangkan dan dapat memancing reaksi emosinya. Perubahan mood yang sangat fluktuatif dan perasaan tidak bahagia yang biasanya menyertai perjalanan penyakit hipertensi semakin berkurang. Perubahan emosi negatif ke emosi positif ternyata menimbulkan dampak yang signifikan terhadap kehidupan sosial penderita hipertensi. Hubungan dengan orang lain menjadi lebih baik dan aktivitas sosial pun mulai dijalankan karena berkurangnya rasa nyeri yang selama ini dirasakan.(Aswad \& Susanto, 2019)

\section{KESIMPULAN DAN SARAN}

Relaksasi dengan metode lima jari pasien akan dibimbing untuk merasakan kebahagian melalui persepsi yang dibangun untuk dirinya, bagaimana kebahagiaan di tempat yang disukai bersama orang yang dicintai, mendapat apresiasi sehingga akan membuat pasien merasa bahagia, mengurangi gangguan fisik dan psikologinya sehingga mengaktifkan endorpin yang membuat pasien bahagia. Pasien yang bahagia akan membantu menurunkan menstabilkan tekanan darah. Relaksasi yang diajarkan akan memstimulus tubuh tidur lebih cepat dengan kondisi tubuh yang rileks dan tenang.

\section{REFERENSI}

Arthaeski, N. P. D. (2019). Gambaran asuhan keperawatan pemberian terapi relaksasi lima jari untuk menurunkan ansietas pada Pasien Gagal Ginjal kronis yang sedanag dilakukan hemodialisa di RSUD Sanjiwani
Gianyar Tahun2019. Politeknik Kesehatan Kemenkes Denpasar Jurusan Keperawatan.

Aswad, Y., \& Susanto, B. (2019). Pengaruh Imajinasi Terbimbing Terhadap Tekanan Darah Pendierita Hipertensi Di Panti Wirda Ilomata. Jambura Journal of Health Sciences and Research, 1(1), 7-12.

Black, J. M., \& Hawks, J. H. (2021). Medical Surgical Nursing: Elimination, Renal and Urinary Systems Disorders. Elsevier Health Sciences.

Brunner, L. S. (2010). Brunner \& Suddarth's textbook of medical-surgical nursing (Vol. 1). Lippincott Williams \& Wilkins.

Depkes RI. (2018). Riset Kesehatan Dasar.

Essy, M. (2019). Asuhan Keperawatan pada Ny. $\mathrm{N}$ dengan Ansietas dan Manajemen Kasus Pendidikan Kesehatan Ansietas pada Penderita Hipertensi di RW 03 Kelurahan Cupak Tangah Kota Padang. Universitas Andalas.

Handayani, R. S., \& Rahmayati, E. (2017). Faktor faktor yang berhubungan dengan kualitas hidup pasien Chronic Kidney Disease (CKD) yang menjalani hemodialisis. Jurnal IImiah Keperawatan Sai Betik, 9(2), 238-245.

Hemodialisis, K. Y. M., \& Sari, K. M. (n.d.). Prevalensi Faktor Risiko Penyakit Kardioserebrovaskuler pada Pasien Penyakit Ginjal.

Husaini, F. (2020). Studi Literatur Identifikasi Faktor-faktor yang berhubungan dengan Kepatuhan HD pada Pasien Hemodialisa di Indonesia. Universitas Muhammadiyah Malang.

Lutfiani, D., \& Kurnia, A. (2021). Penurunan Tekanan Darah Dengan Intervensi Terapi Murottal Surah Ar Rahman Pada Penderita Chronic Kidney Disease (CKD). Ners Muda, 2(1), 17-23.

Muhammadiyah, K. (2017). Pengaruh Tehnik 5 Jari Terhadap Tingkat Ansietas Klien Gangguan Fisik Yang Dirawat Di RSU Kendal. Jurnal Keperawatan Muhammadiyah, 1, 2.

Sulistyarini, I. (2013). Terapi relaksasi untuk 
Hapsari, et al., Pengaruh Relaksasi Lima Jari terhadap.... SJKP, Vol. 8, No. 1, Juni 2021, 34-39

menurunkan tekanan darah dan meningkatkan kualitas hidup penderita hipertensi. Jurnal Psikologi, 40(1), 28-38.
Taruna, A. (2014). Penyakit Ginjal Kronik Derajat V. Jurnal Medula, 2(03), 21-30. 